\begin{tabular}{|c|c|c|c|c|c|c|}
\hline \multirow{4}{*}{ Impact Factor: } & ISRA (India) & $=3.117$ & SIS (USA) & $=0.912$ & ICV (Poland) & $=6.630$ \\
\hline & ISI (Dubai, UAE & $=0.829$ & РИНЦ (Russia & $=0.156$ & PIF (India) & $=1.940$ \\
\hline & GIF (Australia) & $=0.564$ & ESJI (KZ) & $=8.716$ & IBI (India) & $=4.260$ \\
\hline & JIF & $=1.500$ & SJIF (Morocce & $=5.667$ & OAJI (USA) & $=0.350$ \\
\hline
\end{tabular}

SOI: $1.1 /$ TAS $\quad$ DOI: $10.15863 /$ TAS

International Scientific Journal Theoretical \& Applied Science

p-ISSN: 2308-4944 (print) e-ISSN: 2409-0085 (online)

Year: 2019 Issue: $05 \quad$ Volume: 73

Published: $30.05 .2019 \quad$ http://T-Science.org

SECTION 32. Jurisprudence.
QR - Issue

QR - Article
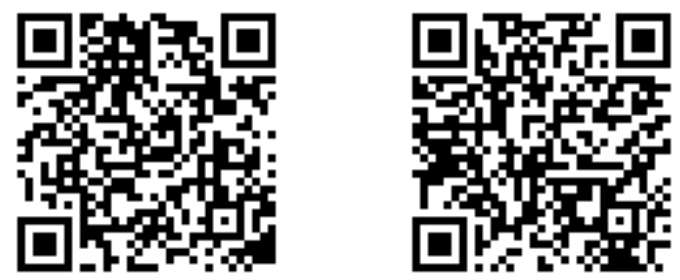

J. T. Aydarbekov assistant of professor of the department of criminal procedure in Academy of Ministry of Internal Affairs of the Kyrgyz Republic candidate of law, colonel of militia

Asel Manapovna Tagaeva professor of the department of criminology, psychology and special equipment, in Academy of Ministry of Internal Affairs of the Kyrgyz Republic candidate of law, colonel of militia

\title{
TO THE QUESTION OF ACTUAL ASPECTS OF THE INVESTIGATION ACTION IN THE CRIMINAL PROCEDURE LEGISLATION OF THE KYRGYZ REPUBLIC
}

Abstract: This article deals with the formation of the concept and meaning of investigative actions, the analysis of the definition of investigative action, as the new code of criminal procedure of the Kyrgyz Republic provides a clear definition: "investigative action" - actions to collect and study information relevant to the case, carried out by an authorized official of the body of inquiry, investigator, Prosecutor in the established code of criminal procedure of the Kyrgyz Republic.

Key words: criminal procedure, criminology, investigative action, procedural action, investigator, evidence gathering, information gathering, pre-trial proceedings.

Language: Russian

Citation: Aydarbekov, J. T., \& Tagaeva, A. M. (2019). To the question of actual aspects of the investigation action in the criminal procedure legislation of the Kyrgyz republic. ISJ Theoretical \& Applied Science, 05 (73), $583-$ 586.

Soi: http://s-o-i.org/1.1/TAS-05-73-92 Doi: crossef https://dx.doi.org/10.15863/TAS.2019.05.73.92

\section{К ВОПРОСУ ОБ АКТУАЛЬНЫХ АСПЕКТАХ СЛЕДСТВЕННОГО ДЕЙСТВИЯ В УГОЛОВНО- ПРОЦЕССУАЛЬНОМ ЗАКОНОДАТЕЛЬСТВЕ КЫРГЫЗСКОЙ РЕСПУБЛИКИ}

Аннотация: В данной статье рассматриваются вопросы формирования понятия и значения следственных действий, проведен анализ по дефиниции следственного действия, так как в новом УПК Кьргызской Республики даётся четкое соответствующее определение: "следственное действие» действия по собиранию и исследованию сведений, имеющих значение для дела, осуществляемые уполномоченным должностным лицом органа дознания, следователем, прокурором в установленном УПК Кыргызской Республики порядке.

Ключевые слова: уголовный прочесс, криминалистика, следственное действие, прочессуальное действие, следователь, собирание доказательств, сбор информации, досудебное производство.

\section{Introduction}

На современном этапе развития государственной власти одним из важнейших общегосударственных задач является укрепление правопорядка и борьба с преступностью.
В науке понятие «следственные действия» понимаются по-разному, тем более что действующим УПК Кыргызской Республики, который вступил в законную силу с 1 января 2019 году, где в п. 40 ст. 5 даётся понятие следственным 


\begin{tabular}{llllll} 
& ISRA (India) $=\mathbf{3 . 1 1 7}$ & SIS (USA) $=\mathbf{0 . 9 1 2}$ & ICV (Poland) & $\mathbf{= 6 . 6 3 0}$ \\
Impact Factor: & ISI (Dubai, UAE) $=\mathbf{0 . 8 2 9}$ & PUHЦ (Russia) $=\mathbf{0 . 1 5 6}$ & PIF (India) & $=\mathbf{1 . 9 4 0}$ \\
& GIF (Australia) $=\mathbf{0 . 5 6 4}$ & ESJI (KZ) & $\mathbf{8 . 7 1 6}$ & IBI (India) & $=\mathbf{4 . 2 6 0}$ \\
& JIF & $\mathbf{1 . 5 0 0}$ & SJIF (Morocco) $=\mathbf{5 . 6 6 7}$ & OAJI (USA) & $\mathbf{0 . 3 5 0}$ \\
\hline
\end{tabular}

действиям, как определенным действиям, направленным на собирание и исследование фактов и обстоятельств, имеющих важное значение при расследовании уголовного дела, производимые уполномоченным должностным лицом органа дознания, следователем, прокурором в предусмотренном УПК Кыргызской Республики порядке [1].

\section{Materials and Methods}

Следственные действия являются разновидностью процессуальных действий, которых нужно отделять от так называемых иных процессуальных действий. Многие учёные отмечают, что особое значение следственных действий заключается в том, что благодаря их исключительным признакам именно они, по сути, должны являться основным способом доказывания, так как это направлено на получение доказательств, который являются основным критерием для отделения следственных действий от иных процессуальных действий [2, с. 38]. Сам термин «следственные действия» находит свое предназначение в классической континентальной уголовно-процессуальной терминологии, которая всегда подчеркивает свою связь того или иного процессуального института с процессом доказывания.

Следовательно, следственное действие - это часть процессуального действия.

Но в свою очередь, процессуальная деятельность следователя характерна признакам, позволяющим ей беспрепятственно существовать в пределах уголовного процесса наряду с должностными лицами (прокурором, руководителем следственного органа и т.д.).

Характерными признаками следственных действий являются:

1) активность, которая выражается в эффективном использовании процессуальных правил и соответствующих научно-технических средств субъектом проведения;

2) четкость целей, которые направлены на достижение определенных задач;

3) определенная структура;

4) реализация задач следственного действия определенными субъектами уголовного процесса, несущими ответственность за расследование уголовного дела;

5) определенная процессуальная форма, предопределяющая правила проведения какихлибо процессуальных мероприятий и действий.

Указанные выше характерные признаки присущи процессуальной деятельности в целом, поэтому они являются и характерными признаками следственных действий, осуществляемых следователем по правилам, установленным УПК Кыргызской Республики.

В соответствии ч. 1 ст. 93 УПК Кыргызской Республики, собирание доказательств осуществляется в уголовном судопроизводстве путём производства процессуальных действий [1].

Некоторые учёные в следственных действиях усматривают оценочную сущность. Другие ученые под сущностью следственных действий предусматривают сам процесс собирания доказательственной информации. С.А. Шейфер под следственным действием понимает совокупность познавательных операций, предусмотренных для эффективного собирания доказательств, то есть отыскания, восприятия и закрепления имеющейся в предметах преступления и вещественных доказательствах значимой доказательственной информации [3, с. 23]. Другие учёные в понимании следственных действий имеют в виду процесс проверки доказательств на достоверность [4, с. 20].

Таким образом, было правильно объединить мнения всех ученых и сформулировать понятие следственного действия следующим образом: следственные действия являются предусмотренными УПК Кыргызской Республики конкретные действия следователя, уполномоченного должностного лица органа дознания, направленные на выявление признаков преступления, собирание и проверку доказательств. Они характеризуются определенными признаками, специальной процедурой проведения и процессуального оформления их результатов, обеспечивающиеся уголовно-процессуальным принуждением.

При этом справедливо отмечает С.Б. Россинский, что собирание и проверка доказательственной информации являются процессами, не связанными с целями и задачами следственных действий, а связаны скорее с содержательным наполнением, представляющим собой получение и закрепление доказательственной информации [5, с. 20]. Целью следственных действий является выявление новых сведений. Думается, что такой подход позволит усмотреть в них поисковопознавательную сущность и отграничить следственные действия от других процессуальных мероприятий, предусмотренных для собирания и закрепления доказательств. В УПК Кыргызской Республики не предусмотрено единого перечня следственных действий, в связи с чем, практикам и теоретикам предоставляется негласное право отнесения определенных процессуальных мероприятий к конкретным следственным действиям. 


\begin{tabular}{llllll} 
& ISRA (India) $=\mathbf{3 . 1 1 7}$ & SIS (USA) $=\mathbf{0 . 9 1 2}$ & ICV (Poland) & $\mathbf{= 6 . 6 3 0}$ \\
Impact Factor: & ISI (Dubai, UAE) $=\mathbf{0 . 8 2 9}$ & PUHЦ (Russia) $=\mathbf{0 . 1 5 6}$ & PIF (India) & $=\mathbf{1 . 9 4 0}$ \\
& GIF (Australia) $=\mathbf{0 . 5 6 4}$ & ESJI (KZ) & $\mathbf{8 . 7 1 6}$ & IBI (India) & $=\mathbf{4 . 2 6 0}$ \\
& JIF & $\mathbf{1 . 5 0 0}$ & SJIF (Morocco) $=\mathbf{5 . 6 6 7}$ & OAJI (USA) & $\mathbf{0 . 3 5 0}$ \\
\hline
\end{tabular}

Например, О.Я. Баев включил в систему следственных действий: следственный осмотр и его разновидностью определяет освидетельствование; обыск и выемку; допрос и его разновидностью определяет очную ставку; следственный эксперимент как самостоятельное следственное действие, а также осуществляемый путем воспроизводства и проверки показаний на месте; предъявление для опознания; назначение судебных экспертиз [6, с. 34].

А.М. Ларин и И.Ф. Герасимов, предусматривая конкретную деятельность субъектов расследования, считают, что любые действия следователя, которые тот осуществляет в соответствии с требованиями УПК, являются следственными действиями [7, с. 206].

И.Е. Быховский и некоторые процессуалисты рассматривали следственное действие, давая ему более узкое понятие, полагая, что термин «следственное действие» необходимо рассматривать не по субъектам расследования, а по их содержательной деятельности, потому что, процессуальная деятельность следователя, по собиранию доказательств, носит не только познавательный, но и исследовательский характер [8, с. 108]. По их мнению, к следственным действиям относится лишь некоторые процессуальные действия, имеющие познавательный и оценочный характер.

Аналогичное мнение можно обнаружить и в других источниках, где следственными действиями называются такие процессуальные действия, которые направлены на собирание доказательств [9, с. 127].

Имеющаяся проблема о правильном толковании следственных действий и их видах является довольно актуальной на сегодняшний день и продолжает быть дискуссионной темой. Считаем, что в рамках реформирования Уголовнопроцессуального законодательства пришло время для законодательной регламентации вышеуказанных спорных вопросов. В частности, полагаем целесообразным закрепление в УПК Кыргызской Республики самого понятия «следственные действия» и предусмотреть конкретные их виды в самостоятельной статье. Законодательное закрепление этих понятий, будет иметь как теоретическое, так практическое значение. Внесение ясности и предусмотрение четких понятий следственных действий и их видов позволит предотвратить некоторые нарушения, имеющие место в следственной практике:

процессуальные нарушения прав участников следственных действий,

$$
\text { исключить подмену конкретных }
$$
следственных действий иными процессуальными мероприятиями;
- устранить угрозу невозможности допустимости полученных доказательств.

Таким образом, в законе должно быть предусмотрено развернутое понятие следственных действий и их видов. Данным пробелом в уголовно-процессуальном законодательстве обосновываются сложности, возникающие в научных объяснениях и дальнейших изысканиях новых форм закрепления следственных действий. Кроме того, при формировании нового понятия «следственное действие» его необходимо рассматривать и в криминалистическом аспекте, потому как криминалистика является прикладной наукой, вносящей огромный вклад в борьбу с преступностью.

Общеизвестно, что теория криминалистики тесно связана с уголовным процессом. А.Н. Васильев и Н.П. Яблоков считают, что эти две науки объединяют общие цели и задачи «проведение в жизнь требований уголовнопроцессуального закона по расследованию и предупреждению преступлений и соприкосновение их научных положений, а также рекомендаций, разрабатываемых для практики» $[10$, c. 12$]$.

Отграничить науку криминалистику вместе с криминалистической тактикой от уголовного процесса, отталкиваясь от наличия в этих науках предметов исследования невозможно. Следует четко понимать, что их связывают многочисленные связи, которые доказывают невозможность существования этих двух наук изолированно друг от друга, поскольку они в узком смысле являются смежными науками, что предусматривает процесс их взаимопроникновения [11, с. 40].

Итак, юридическая литература в различных модификациях и проявлениях научной мысли содержит довольно четкое суждение о следственном действии, как о деятельности следователя, направленной на собирание, исследование, проверку доказательств. Действия следователя, не связанные со сбором, анализом и проверкой доказательств, необходимо правильно обозначать термином «процессуальные» или «иные действия» следователя [12, с. 234 - 235].

По нашему мнению, связь криминалистики и уголовного процесса непременно существует, поскольку уголовный процесс предусматривает определенные следственные действия, а криминалистика разрабатывает тактику их производства, в целом оптимизирует процесс расследования путем предоставления конкретных рекомендаций для различных видов следственных действий с учетом особенностей их производства. 


\begin{tabular}{|c|c|c|c|c|c|c|}
\hline \multirow{4}{*}{ Impact Factor: } & ISRA (India) & $=3.117$ & SIS (USA) & $=0.912$ & ICV (Poland) & $=6.630$ \\
\hline & ISI (Dubai, UAE & $=0.829$ & РИНЦ (Russia & $=0.156$ & PIF (India) & $=1.940$ \\
\hline & GIF (Australia) & $=0.564$ & ESJI (KZ) & $=8.716$ & IBI (India) & $=4.260$ \\
\hline & JIF & $=1.500$ & SJIF (Morocce & $=5.667$ & OAJI (USA) & $=0.350$ \\
\hline
\end{tabular}

Развитие и обновление теории криминалистики обосновывает необходимость разработки для каждого следственного действие изначально определенных тактических приемов, стремящихся получить процессуальную «оболочку».

\section{Conclusion}

Резюмируя все вышеизложенное, можно отметить, что рассмотренные специфические тактические особенности следственных действий можно определить как конкретные способы реализации уголовно-процессуальных функций следователя, которые обусловливаются необходимостью тщательно соблюдать определенную процессуальную форму, грамотно устанавливать основания их проведения, исходя из принципов исключения возможностей угрозы нарушений прав, свобод и законных интересов граждан, вовлеченных в стадию досудебного производства по уголовному делу.

Следовательно, можно сделать вывод о том, что от правильного производства следственных действий зависит успех досудебного производства, а в целом вся эффективная система правосудия по уголовным делам. Поэтому практические работники нуждаются в надёжных знаниях о сущности следственных действий, их участниках, применяемых познавательных способах и приёмах получения сведений об обстоятельствах совершённого преступления, связи их с допустимостью доказательств, других важнейших аспектах.

\section{References:}

1. (2017). Ugolovno-processual'nyj kodeks Kyrgyzskoj Respubliki ot 02.02.2017. № 20 (vvedennyj $\mathrm{v}$ dejstvie Zakonom KR ot 24 yanvarya 2017 goda № 10 s 1 yanvarya 2019 goda). Retrieved 2019, from http://cbd.minjust.gov.kg/act/view/ru-ru/111530

2. Zhumabekova, T. A. (2014). Sledstvennye dejstviya. Bishkek.

3. Shejfer, S. A. (2004). Sledstvennye dejstviya. Osnovaniya, processual'nyj poryadok $i$ dokazatel'stvennoe znachenie. Samara.

4. Yanovskij, R. S. (2013). Aktual'nye problemy proizvodstva sledstvennyh dejstvij $v$ rossijskom ugolovnom processe: avtoref. dis... kand. yurid. nauk. Moskva.

5. Rossinskij, S. B. (2015). Ponyatie i sushchnost' sledstvennyh dejstvij $v$ ugolovnom sudoproizvodstve: diskussiya prodolzhaetsya. Zakony Rossii. Opyt. Analiz. Praktika. № 2.
6. Baev, O. Y. (2013). Taktika sledstvennyh dejstvij: Uchebnoe posobie. Moscow.

7. (1998). Ugolovnyj process: uchebnik dlya vuzov / pod red. K.F. Gucenko (Eds.). Moscow.

8. Byhovskij, I. E. (1972). Razvitie processual'noj reglamentacii sledstvennyh dejstvij. Sovetskoe gosudarstvo i parvo, № 4.

9. (2004). Ugolovno-processual'noe parvo. pod red. P.A. Lupinskoj (Eds.). Moscow.

10. Vasil'ev, A. N., \& Yablokov, N. P. (1984). Predmet, sistema $i$ teoreticheskie osnovy kriminalistiki. Moscow.

11. Ginzburg, A. Y., \& Belkin, A. R. (1998). Kriminalisticheskaya taktika: uchebnik / pod obshch.red. A.F. Aubakirova (Eds.). Almaty.

12. Komissarov, V. I. (1988). Aktual'nye problemy sledstvennoj taktiki: dis. ... d-ra yurid. nauk. Saratov. 